\title{
EVALUASI KESESUAIAN LAHAN TAMBAK GARAM MENGGUNAKAN INDEKS KESESUAIAN LAHAN GARAM (IKLG) DI DESA TLUWUK, PATI
}

\author{
Land Suitability Evaluation for Salt Ponds Using Salt Suitability Index (IKLG) in \\ Tluwuk Village, Pati
}

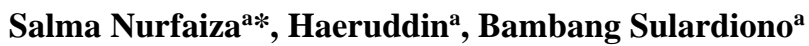 \\ ${ }^{a}$ Program Studi Manajemen Sumberdaya Perairan, Departemen Sumberdaya Akuatik \\ Fakultas Perikanan dan Ilmu Kelautan Universitas Diponegoro \\ J1. Prof Soedarto, SH, Tembalang, Semarang, Jawa Tengah-50275, Telp/Fax +6224 7474698
}

*Koresponden penulis: salma.nrfz26@gmail.com

\begin{abstract}
Abstrak
Garam merupakan komoditas ekonomis penting di Indonesia. Tambak garam merupakan salah satu bentuk pemanfaatan wilayah pesisir. Akan tetapi, wilayah pesisir di Indonesia tak semuanya dapat dimanfaatkan sebagai tambak garam. Kabupaten Pati merupakan salah satu wilayah yang berpotensi sebagai lokasi tambak garam. Lokasi penelitian ini adalah tambak garam di Desa Tluwuk, Kecamatan Wedarijaksa. Tambak garam di lokasi tersebut masih menghasilkan kualitas dan produktivitas garam yang kurang optimal. Hal ini dimungkinkan karena pemilihan lokasi yang kurang sesuai untuk dijadikan lahan tambak garam serta pembangunan infrastruktur yang kurang baik. Tujuan penelitian ini adalah untuk mengevaluasi kesesuaian lahan tambak garam di Desa Tluwuk, Kecamatan Wedarijaksa, Kabupaten Pati. Penelitian dilakukan pada bulan Juli-Agustus, 2020. Metode sampling yang digunakan adalah Pengambilan Sampel Acak Berlapis (Stratified Random Sampling). Analisis data yang digunakan adalah teknik skoring dengan menganalisis parameter fisika dan kimia lahan tambak garam dan melakukan skoring serta perhitungan indeks kesesuaian lahan garam. Hasil penelitian menunjukkan bahwa kesesuaian lahan tambak garam di Desa Tluwuk termasuk kategori sangat sesuai dengan Indeks Kesesuaian Lahan Garam (IKLG) 85\% untuk tambak yang terdekat dari pantai dan kategori sesuai dengan IKLG 68\% untuk tambak yang terjauh dari pantai.
\end{abstract}

Kata kunci: Evaluasi Kesesuaian Lahan, IKLG, Tambak Garam

\begin{abstract}
Salt is an important economic commodity in Indonesia. Salt ponds are one form of utilization of coastal areas. However, coastal areas in Indonesia can not all be used as salt ponds. Pati Regency is one of the regions that have the potential to be used as a salt pond location. The location of this research is salt ponds in Tluwuk Village, Wedarijaksa District. Salt ponds in that location, did not produce a good quality and productivity of salt. This is possibly happened because of the selection of locations that are not suitable to be used as salt ponds as well as poor infrastructure development. The purposes of this study was to evaluate the land suitability of the salt pond in Tluwuk Village, Wedarijaksa District, Pati Regency. The research was conducted in July-August 2020. The sampling method used is stratified random sampling. The data analysis technique used is the scoring technique by analyzing the physical and chemical parameters of the salt pond, also performing the calculation of salt suitability index. The result of this study showed that the suitability of salt pond in Tluwuk Village belongs to the category very suitable with Salt Pond Suitability Index (IKLG) $85 \%$ for ponds near to the beach and suitable with IKLG 68\% for ponds far from the beach.
\end{abstract}

Keywords: Land Suitability Evaluation, IKLG, Salt Pond

\section{PENDAHULUAN}

Indonesia merupakan negara yang berpotensi untuk bahan baku pembuatan garam. Garam di Indonesia diproduksi dengan memanfaatkan air laut ataupun air payau. Lokasi produksi garam di Indonesia biasanya sangat dekat dengan sumber bahan bakunya seperti langsung dari laut atau aliran sungai berair payau [1]. 
Kabupaten Pati merupakan salah satu kabupaten di Provinsi Jawa Tengah yang memiliki potensi sebagai lokasi pengembangan lahan tambak garam dengan Luas lahan total tambak garam pada tahun 2018 mencapai 2.838,11 ha. Kabupaten Pati memiliki 4 kecamatan yang berpotensi tinggi dalam pengembangan lahan tambak garam, salah satunya adalah Kecamatan Wedarijaksa. Desa yang mempunyai potensi tertinggi untuk pengembangan lahan tambak garam di Kecamatan Wedarijaksa adalah Desa Tluwuk. Luasan tambak garam di Desa Tluwuk adalah 210,46 Ha. Terdapat 2 dari 8 unit gudang garam bantuan pemerintah Kabupaten Pati terletak di Desa Tluwuk. Selain itu, terdapat 450 unit gudang garam rakyat di Desa Tluwuk yang merupakan jumlah kedua terbanyak di Kabupaten Pati [2].

Tambak garam merupakan kolam dangkal buatan yang dirancang untuk menghasilkan garam dari air laut atau air asin lainnya. Perancangan untuk membuat tambak garam ini dibuat di lokasi yang memenuhi kriteria lahan secara fisika ataupun kimia. Prosedur dalam pembuatan garam menggunakan tambak garam bervariasi berdasarkan wilayah geografis dan tergantung pada ketersediaan sumber daya dalam hal ini adalah air laut [3].

Garam merupakan padatan berwarna putih yang biasanya berbentuk kristal. Garam secara alami mengandung beberapa senyawa dengan penyusun terbesar yaitu Natrium Klorida $(\mathrm{NaCl})$ dan pengotor yaitu Kalsium Sulfat $\left(\mathrm{CaSO}_{4}\right)$, Magnesium Sulfat $\left(\mathrm{MgSO}_{4}\right)$, dan Magnesium Klorida $\left(\mathrm{MgCl}_{2}\right)$. Kadar $\mathrm{NaCl}$ dari garam tidak hanya ditentukan oleh salinitas dan kandungan $\mathrm{NaCl}$ air baku tetapi dipengaruhi pula oleh beberapa faktor seperti kualitas air laut, zat pengotor dan serta jenis dasar meja garam [4].

Pembuatan garam secara tradisional dengan metode penguapan air laut dengan memanfaatkan sinar matahari dilakukan melalui 4 tahapan proses. Tahap pertama adalah pengolahan air laut yang diawali dengan mengisikan air laut ke dalam kolam tandon yang dilanjutkan dengan penguapan hingga mencapai kepekatan $11,5 \mathrm{Be}$. Tahap kedua adalah pengaliran air yang sudah mencapai kepekatan tersebut ke kolam peminihan hingga mencapai ketinggian $35 \mathrm{~cm}$. Air laut ini selanjutnya dilakukan penguapan kembali dengan Teknik Ulir Garam (TUG) hingga mencapai kepekatan $22^{\circ} \mathrm{Be}$. Tahap ketiga adalah pengolahan air tua sebelum masuk ke meja garam. Air tua merupakan air yang sudah siap untuk dilakukan proses kristalisasi. Air yang sudah mencapai kepekatan $22-25^{\circ} \mathrm{Be}$, dialirkan ke Meja Garam hingga ketinggian 12 $\mathrm{cm}$. Penguapan dilanjutkan di Meja Garam hingga mencapai kepekatan $25-29^{\circ} \mathrm{Be}$. Tahap terakhir adalah proses pungutan. Pungutan ini dilakukan secara perlahan dengan tebal air Meja 3-5 cm setelah itu ditiriskan dari sisa air [5].

Tambak garam di Kabupaten Pati masih menghasilkan kualitas garam dan produktivitas lahan garam yang kurang optimal. Hal ini dimungkinkan karena pemilihan lokasi yang kurang sesuai untuk dijadikan lahan tambak garam serta pembangunan infrastruktur yang kurang baik. Permasalahan tersebut yang menyebabkan diperlukan adanya penelitian mengenai evaluasi kesesuaian lahan tambak garam berdasarkan parameter fisika kimia.

\section{METODE PENELITIAN}

\section{Materi}

Materi yang digunakan dalam penelitian ini adalah konstruksi fisik tambak, tanah dasar tambak dan air garam yang diukur dan diambil dari lokasi penelitian.

\section{Metode Sampling}

Metode sampling yang digunakan adalah Pengambilan Sampel Acak Berlapis (Stratified Random Sampling). Tujuan metode ini adalah untuk mengurangi variasi dalam lapisan tertentu. Metode sampling ini digunakan dengan membagi populasi menjadi beberapa lapisan yang kemudian dilakukan pemilihan titik secara acak untuk pengambilan sampel [6]. Pembagian lapisan dilakukan berdasarkan jarak tambak dari pantai. Stasiun 
lokasi sampling yang dipilih yaitu tambak dengan jarak terdekat dan terjauh dari pantai. Perbedaan jarak tambak ke pantai ini menyebabkan perbedaan penggunaan saluran air laut yang digunakan untuk bahan baku proses produksi garam.

Tabel 1. Stasiun Lokasi Penelitian

\begin{tabular}{lccc}
\hline \multirow{2}{*}{$\begin{array}{c}\text { Stasiun } \\
\text { Lokasi }\end{array}$} & \multicolumn{2}{c}{ Posisi Koordinat } & $\begin{array}{c}\text { Jarak } \\
\text { ke }\end{array}$ \\
\cline { 2 - 3 } Penelitian & $\begin{array}{c}\text { Lintang } \\
\text { Selatan }\end{array}$ & $\begin{array}{c}\text { Bujur } \\
\text { Timur }\end{array}$ & $\begin{array}{c}\text { Pantai } \\
(\mathrm{km})\end{array}$ \\
\hline $\begin{array}{l}\text { Tambak } \\
\text { Dekat }\end{array}$ & $06^{\circ}$ & $111^{\circ}$ & \\
Pantai & $40^{\prime} 54.2^{\prime \prime}$ & $06^{\prime} 34.6^{\prime \prime}$ & 0,41 \\
$\begin{array}{l}\text { Tambak } \\
\text { Jauh } \\
\text { Pantai }\end{array}$ & $06^{\circ} 39^{\prime} 16.6^{\prime \prime}$ & $111^{\circ} 08^{\prime} 33.6^{\prime \prime}$ & 5,12 \\
\hline
\end{tabular}

Pemilihan tambak terdekat dari pantai dilakukan dengan menentukan satu petakan yang sudah aktif melakukan proses produksi garam dengan lokasi paling dekat dengan bibir pantai. Satu petakan ini terdiri dari kolam tandon, 5 kolam peminihan, kolam air tua dan 4 meja garam. Stasiun ini menggunakan saluran air buatan untuk mendapatkan air laut yang berdampingan dengan muara sungai. Di sekitar stasiun penelitian ini terdapat banyak pohon mangrove dan aliran muara sungai yang digunakan untuk pemancingan.

Sama halnya dengan pemilihan tambak terjauh dari pantai, yaitu dilakukan dengan menentukan satu petakan yang sudah aktif memproduksi garam dengan lokasi paling jauh dengan pantai. Satu petakan ini terdiri dari kolam tandon, kolam peminihan, kolam air tua dan 4 meja garam. Stasiun ini menggunakan saluran air berupa sungai buatan untuk mendapatkan air laut yang berdampingan dengan sungai air tawar. Di sekitar stasiun penelitian ini terdapat area persawahan dan tambak perikanan seperti tambak udang dan bandeng.

Terdapat 2 Parameter dengan 11 Variabel penelitian. Pengamatan parameter fisika dilakukan pada 9 variabel. Pengukuran tinggi pematang utama, tinggi pematang antara, dimensi pematang antara dan ketinggian air meja garam menggunakan alat roll meter dan penggaris. Pengukuran ${ }^{\circ} \mathrm{Be}$ kolam peminihan, kolam air tua dan meja garam diukur dengan Baume meter. Pengukuran jarak dari pantai menggunakan data sekunder. Pengamatan tekstur dasar tambak dilakukan dengan mengambil sampel tanah dasar tambak dan dilakukan analisis di laboratorium. Pengamatan parameter kimia yaitu: $\mathrm{pH}$ dan konsentrasi $\mathrm{SO}_{4}$. Pengukuran $\mathrm{pH}$ dilakukan secara insitu dengan indikator $\mathrm{pH}$ universal. Pengukuran konsentrasi $\mathrm{SO}_{4}$ dilakukan secara exsitu dengan mengambil sampel air dan diukur di Laboratorium Mutu Air dan Lingkungan Balai Pengujian dan Peralatan Provinsi Jawa Tengah.
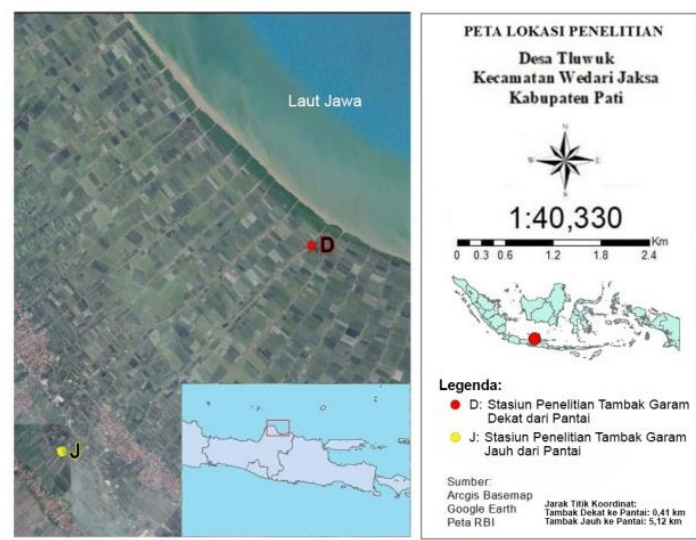

Gambar 1. Peta Lokasi Penelitian

\section{Metode Analisis Data}

Analisis data yang digunakan untuk mengevaluasi kesesuaian lahan tambak garam dalam penelitian ini adalah teknik analisis skoring. Teknik analisis skoring digunakan untuk memberikan nilai pada setiap karakteristik parameter dari sub-sub variabel agar dapat dihitung nilainya serta dapat ditentukan peringkatnya. Tahapan analisis data menggunakan teknik analisis skoring ini dibagi menjadi beberapa tahap [7] yaitu:

1. Pembagian dan Penentuan Kelas Kesesuaian.

Setiap variabel dari parameter diberikan tingkatan dari kelas sangat sesuai, cukup sesuai, dan tidak sesuai. Kelas sangat sesuai (S1) diberikan skor 3, kelas sesuai (S2) 
diberikan skor 2, dan kelas tidak sesuai $(\mathrm{N})$ diberikan skor 1. Jumlah variabel yang digunakan dalam penelitian kali ini sebanyak 11 variabel. Penentuan kelas kesesuaian lahan tambak garam tersaji pada Tabel 2.

2. Pembobotan Variabel.

Bobot yang digunakan sangat tergantung dari percobaan atau pengalaman empiris yang telah dilakukan. Pembobotan dilakukan dengan mengamati kepentingan suatu variabel terhadap keberhasilan suatu faktor. Pembobotan kali ini mengamati kepentingan suatu variabel terhadap keberhasilan pengembangan produksi garam yang dilihat dari kualitas garam dan produktivitas tambak garam. Bobot yang diberikan adalah 5, 3 dan 1 tergantung kepentingan variabel terhadap suatu faktor [8]. Kriteria untuk masing-masing pembobotan (Tabel 3.) adalah:

a. Pemberian bobot 5 didasari oleh unsur variabel sangat diperlukan atau merupakan variabel kunci.

b. Pemberian bobot 3 didasari oleh unsur variabel sedikit diperlukan atau merupakan variabel cukup penting.

c. Pemberian bobot 1 didasari oleh unsur variabel tidak begitu penting atau tanpa adanya parameter tersebut, kegiatan dapat tetap berjalan.

Tabel 2. Pembagian Kelas Variabel Kesesuaian Lahan Tambak Garam [7]

\begin{tabular}{clccc}
\hline \multirow{2}{*}{ No } & \multirow{2}{*}{ Variabel Karakteristik Lahan } & \multicolumn{3}{c}{ Kelas Kesesuaian Lahan } \\
\cline { 3 - 5 } & & $\mathrm{S} 1: 3$ & $\mathrm{~S} 2: 2$ & $\mathrm{~N}: 1$ \\
\hline 1 & $\mathrm{SO}_{4}(\mathrm{mg} / \mathrm{L})$ & 0 & 0 & $>0,001$ \\
2 & $\mathrm{pH}$ & $7-8$ & 9 & $<6$ \\
3 & Tinggi pematang utama $(\mathrm{m})$ & $2-2,5$ & $1,5-2$ & $<1,0$ \\
4 & Tinggi pematang antara $(\mathrm{m})$ & $0,25-0,3$ & $0,2-0,25$ & $<0,25$ \\
5 & Ketinggian air meja garam $(\mathrm{cm})$ & $5-10$ & $10-15$ & $>15$ \\
6 & Dasar tambak & Pasir $<20 \%$ & Pasir $<30 \%$ & $>50 \%$ dengan \\
& & dengan sedikit & dengan sedikit & lumpur $>3$ \\
& & lumpur (max 2 & lumpur $2-3$ & $\mathrm{~cm}$ \\
& & $\mathrm{~cm})$ & $\mathrm{cm}$ & $>5.000$ \\
7 & Jarak dari pantai $(\mathrm{m})$ & $300-1.000$ & $1.000-5.000$ & $<20$ \\
8 & Kolam peminihan $\left({ }^{\circ} \mathrm{Be}\right)$ & $3-22$ & $3-20$ & $<22$ \\
9 & Kolam air tua $\left({ }^{\circ} \mathrm{Be}\right)$ & $23-25$ & 22 & $<25$ \\
10 & Meja garam $\left({ }^{\circ} \mathrm{Be}\right)$ & $25-29$ & $25-27$ & \\
11 & Dimensi pematang antara & & Lebar atas 40 & \\
& & Lebar atas 50 & $-50 \mathrm{~cm}$, & Lebar atas \\
& & cm, tinggi & tinggi & $40 \mathrm{~cm}$, tinggi \\
& & minimal 25 cm & minimal 25 & $<25 \mathrm{~cm}$ \\
& & & $\mathrm{~cm}$ & \\
\hline
\end{tabular}

Tabel 3. Pembobotan Variabel Karakteristik Lahan Tambak Garam

\begin{tabular}{clcc}
\hline No. & \multicolumn{1}{c}{ Variabel Karakteristik Lahan } & Bobot & Sumber Pustaka \\
\hline 1 & $\mathrm{SO}_{4}(\mathrm{mg} / \mathrm{L})$ & 3 & {$[9]$} \\
2 & $\mathrm{pH}$ & 3 & {$[10]$} \\
3 & Tinggi pematang utama $(\mathrm{m})$ & 1 & {$[11]$} \\
4 & Tinggi pematang antara $(\mathrm{m})$ & 1 & {$[11]$} \\
5 & Ketinggian air meja garam $(\mathrm{cm})$ & 5 & {$[12]$} \\
6 & Dasar tambak & 5 & {$[13]$} \\
7 & Jarak dari pantai $(\mathrm{m})$ & 5 & {$[14]$} \\
\hline 185 & & & O2021 at http://jfmr.ub.ac.id
\end{tabular}




\begin{tabular}{clcc}
8 & Kolam peminihan $\left({ }^{\circ} \mathrm{Be}\right)$ & 5 & {$[15]$} \\
9 & Kolam air tua $\left({ }^{\circ} \mathrm{Be}\right)$ & 5 & {$[15]$} \\
10 & Meja garam $\left({ }^{\circ} \mathrm{Be}\right)$ & 5 & {$[15]$} \\
11 & Dimensi pematang antara & 1 & {$[11]$} \\
\hline
\end{tabular}

3. Pembobotan skoring.

Pembobotan skoring dilakukan dengan perkalian skor dan bobot tiap variabel yang selanjutnya dilakukan penjumlahan total variabel. Selain itu, dilakukan pula perhitungan jumlah total variabel maksimal dengan menjumlahkan hasil kali skor dan bobot maksimal tiap variabel.

4. Perhitungan Indeks Kesesuaian Lahan Garam (IKLG).

Kesesuaian Lahan Garam ditetapkan berdasarkan nilai dari pembobotan skoring, dengan perhitungan kriteria pada Tabel 4 .

Tabel 4. Kriteria IKLG [7]

\begin{tabular}{lc}
\hline Kriteria & $\begin{array}{c}\text { Indeks Kesesuaian Lahan } \\
\text { Garam }\end{array}$ \\
\hline Sangat Sesuai & $80-100 \%$ \\
Sesuai & $50-79 \%$ \\
Tidak Sesuai & $<49 \%$ \\
\hline
\end{tabular}

Adapun rumus untuk menghitung kesesuaian fisik tambak garam [1], yaitu:

$$
I K G=(\Sigma \mathrm{Ni} / \mathrm{Nmaks}) \times 100 \%
$$

Keterangan:

IKG: Indeks Kesesuaian Lahan Garam

Ni: Nilai Variabel ke-i (bobot x skor)

N maks: Nilai Maksimum dari Suatu Kategori

\section{HASIL DAN PEMBAHASAN}

\section{Karakteristik Lahan Tambak Garam}

Karakteristik lahan tambak garam disusun oleh beberapa komponen diantaranya tanah, air dan bentuk tambak yang dibangun di atasnya. Peruntukan lahan yang sama sebagai tambak garam, seharusnya menjadikan komponen di dalam karakteristik lahan ini menjadi sama. Namun, terdapat beberapa perbedaan hasil pengukuran pada tambak garam yang terletak dekat dari pantai dengan tambak garam yang terletak jauh dari pantai. Hal tersebut dapat terjadi dikarenakan adanya perbedaan sumber aliran air yang masuk serta perbedaan pengelolaan lahan. Perbedaan kedua lokasi produksi garam dengan sumber air berbeda akan sangat dipengaruhi oleh faktor pendukung lainnya seperti jenis tanah dan kejenuhan air bahan baku garam [1].

Berdasarkan hasil pengukuran konsentrasi sulfat, didapatkan hasil yang sangat tinggi di kedua lokasi pengambilan sampel. Hasil tersebut dikategorikan tidak sesuai $(\mathrm{N})$ dikarenakan jauh melebihi batas sesuai. Hasil konsentrasi sulfat di tambak dekat dari pantai lebih besar dibandingkan dengan tambak jauh dari pantai. Hal tersebut dimungkinkan terjadi karena pada saat air mengalir untuk sampai ke tambak jauh dari pantai terjadi penguapan $\mathrm{SO}_{4}$ ke udara atau pengendapan ke sedimen dasar. Selain itu, lokasi tambak yang dekat pantai ini sangat dekat dengan hutan mangrove, yang menyebabkan adanya masukan sulfat dari sedimen sekitar hutan mangrove. Adanya hutan mangrove dan masukan air sungai akibat aktivitas pertanian berpengaruh pada konsentrasi sulfat di perairan [16].

Hasil pengukuran $\mathrm{pH}$ di kedua lokasi menunjukkan hasil cenderung netral. Nilai $\mathrm{pH}$ 6 - 7 yang didapatkan di tambak dekat dari pantai menunjukkan adanya kecenderungan asam dikarenakan adanya hubungan dengan konsentrasi sulfat yang tinggi pula. Hasil $\mathrm{pH}$ cenderung netral pada kedua tambak tersebut menunjukkan air yang digunakan dalam keadaan optimal dan dikategorikan sangat sesuai (S1). Terdapat keterkaitan nilai $\mathrm{pH}$ pada proses produksi garam yaitu terletak pada kualitas garam yang dihasilkan. Kemurnian garam dapat tinggi apabila $\mathrm{pH}$ optimal. Hal ini dikarenakan nilai $\mathrm{pH}$ berpengaruh pada kelarutan senyawa di dalam air baku garam. $\mathrm{pH}$ yang optimal akan menyebabkan kelarutan senyawa yang stabil sehingga dapat membentuk endapan di dasar [10]. 
Berdasarkan pengukuran ketinggian pematang antara, diketahui jika terdapat perbedaan ketinggian sekitar 0,2 meter pada pematang antara di kedua lokasi. Namun keduanya tetap dikategorikan sangat sesuai (S1) karena tingginya yang diatas batas. Biasanya ketinggian pematang juga menyesuaikan aliran air dan tampungan air yang masuk sebelum dimasukkan ke dalam petakan tambak. Maka semakin tinggi pematang antara akan semakin sesuai sebagai konstruksi tambak. Konstruksi pematang terpaksa dibangun tinggi agar dapat menahan air saat pasang tinggi [17].

Tabel 5. Karakteristik Lahan Tambak Garam di Desa Tluwuk

\begin{tabular}{clcc}
\hline No & \multicolumn{1}{c}{ Karakteristik Lahan } & $\begin{array}{c}\text { Tambak Dekat } \\
\text { Pantai }\end{array}$ & Tambak Jauh Pantai \\
\hline 1 & $\mathrm{SO}_{4}(\mathrm{mg} / \mathrm{L})$ & 48.902 & $13.951,2$ \\
2 & pH & $6-7$ & 7 \\
3 & Tinggi pematang utama $(\mathrm{m})$ & 1,5 & 1,5 \\
4 & Tinggi pematang antara $(\mathrm{m})$ & 0,4 & 0,6 \\
5 & Ketinggian air meja garam $(\mathrm{cm})$ & $5-7$ & $6-7$ \\
6 & Dasar tambak & Liat, $3 \%$ Pasir & Liat, $22 \%$ Pasir \\
7 & Jarak dari pantai $(\mathrm{m})$ & 410 & 5.120 \\
8 & Kolam peminihan $\left({ }^{\circ} \mathrm{Be}\right)$ & $10-20$ & $6-18$ \\
9 & Kolam air tua $\left({ }^{\circ} \mathrm{Be}\right)$ & $22-25$ & $22-25$ \\
10 & Meja garam $\left({ }^{\circ} \mathrm{Be}\right)$ & 27 & 26,5 \\
11 & Dimensi pematang antara & Lebar atas $40 \mathrm{~cm}$, & Lebar atas $40 \mathrm{~cm}$, \\
& & tinggi $40 \mathrm{~cm}$ & $\mathrm{tingi} 60 \mathrm{~cm}$ \\
\hline
\end{tabular}

Berbeda halnya dengan pematang utama yang memiliki ketinggian sama yaitu 1,5 meter di kedua lokasi. Ketinggian ini hanya termasuk kategori sesuai (S2). Hal ini dikarenakan kurang tingginya pematang utama tersebut yang dikhawatirkan kurang mampu menahan air saat pasang tertinggi sehingga menyebabkan banjir dan perembesan air ke dalam kolam tambak. Tinggi pematang utama yang hampir setinggi manusia dewasa juga dapat memperjelas batas antar tambak petambak satu dengan lainnya. Karakteristik lokasi pembuatan garam di Indonesia relatif sama, dimana lahan produksi yang dimiliki antar petambak garam satu dengan lainnya saling berdekatan dan melakukan proses produksi garam yang juga relatif sama [1].

Hasil pengukuran dimensi pematang antara didapatkan lebar atas yang tidak terlalu lebar namun dengan tinggi diatas minimal. Sesuai atau tidaknya variabel dimensi pematang ini sangat mengacu pada lebar atas pematang. Sehingga, dengan lebar atas yang hanya $40 \mathrm{~cm}$, pada kedua lokasi termasuk kategori sesuai (S2). Lebar atas pematang menggambarkan ketebalan dan kekokohan dari sebuah pematang. Dimana semakin lebar atas pematang, maka akan semakin kokoh pematang tersebut. Dibutuhkan konstruksi pematang yang lebar dan kokoh agar dapat menahan tekanan air dari dalam atau luar tambak [18].

Ketinggian air meja garam merupakan variabel yang penting dalam proses produksi. Ketinggian air meja garam pada tambak dekat dari pantai yaitu 5-7 cm memiliki rentang yang lebih jauh yaitu selisih $2 \mathrm{~cm}$ dari ketinggian air tertinggi dan terendah. Sementara itu, ketinggian air meja garam pada tambak jauh dari pantai yaitu 6-7 cm memiliki selisih $1 \mathrm{~cm}$ dari ketinggian air tertinggi dan terendah. Hasil tersebut menunjukkan sangat sesuai (S1) dikarenakan air yang ditampung dalam meja garam tidak terlalu tinggi, sehingga air baku di meja garam dapat berubah menjadi garam sebelum air menjadi terlalu tua. Ketinggian air ini akan mempengaruhi laju penguapan air saat proses terbentuknya garam. Penurunan ketinggian air dapat menjadi estimasi dalam pengukuran laju penguapan [1].

Berdasarkan pengukuran variabel dasar tambak, didapatkan hasil berwujud sama 
pada kedua lokasi yaitu liat (clay). Namun, terdapat perbedaan persentase pasir pada kedua lokasi. Tambak dekat dari pantai memiliki persentase pasir yang rendah sehingga termasuk kedalam kategori sangat sesuai (S1). Sedangkan, tambak jauh dari pantai memiliki persentase pasir > $20 \%$ sehingga dikategorikan sesuai (S2). Tanah yang didominasi fraksi pasir akan mempunyai pori besar dan bersifat poros, sedangkan tanah yang didominasi fraksi liat memiliki banyak pori kecil atau tidak poros. Kriteria tekstur dasar tambak garam adalah jenis tanah yang tidak poros untuk menjamin ketersediaan air tua dan pengendapan yang sempurna. Penurunan ketinggian air tua dapat terjadi karena faktor porositas tanah yang tinggi, sehingga air cepat merembes melalui pori - pori tanah. Tekstur tanah yang dibutuhkan dalam proses produksi garam adalah tanah dengan tingkat permeabilitas rendah dan tanah yang tidak mudah retak [19].

Jarak tambak dari pantai merupakan salah satu variabel yang dijadikan pembeda dalam penentuan lokasi pengambilan sampel, dimana lokasi yang dipilih merupakan lokasi tambak yang terdekat dari pantai dan tambak yang terjauh dari pantai. Dalam penilaian kesesuaian lahan tambak, tambak yang dekat dari pantai dikatakan sangat sesuai (S1) sementara tambak yang jauh dari pantai dikatakan tidak sesuai (N). Hal ini dikarenakan sumber air yang digunakan untuk memproduksi garam adalah air laut, sehingga semakin jauh jarak tambak maka semakin jauh pula dengan sumber air. Sumber air yang jauh tersebut dikhawatirkan akan menyebabkan terkontaminasinya air laut dengan air tawar, sehingga dapat menurunkan kejenuhan air laut sebagai bahan baku pembuatan garam. Secara teoritis konsentrasi garam dalam air berasal dari tengah laut dan semakin jauh dari bibir pantai konsentrasinya akan menipis [14].

Kolam peminihan berfungsi sebagai kolam penampungan untuk menaikkan derajat Baume $\left({ }^{\circ} \mathrm{Be}\right)$ dan mengendapkan kotoran sebelum dapat dipindah ke kolam air tua dan meja garam. Kolam peminihan biasanya memiliki variasi ${ }^{\circ} \mathrm{Be}$ tergantung lama penyinaran. Namun, untuk kolam peminihan akhir sebelum ke kolam air tua, ${ }^{\circ} \mathrm{Be}$ ini harus mencapai setidaknya 20-22 ${ }^{\circ}$ Be. Derajat Baume kolam peminihan untuk tambak dekat dari pantai memiliki kategori sesuai (S2), sedangkan untuk tambak jauh dari pantai memiliki kategori tidak sesuai $(\mathrm{N})$. Hal ini disebabkan karena terlalu rendahnya ${ }^{\circ} \mathrm{Be}$ pada kolam penguapan akhir. Air laut di kolam peminihan akhir tidak akan dipompa sebelum konsentrasi mencapai setidaknya $22{ }^{\circ} \mathrm{Be}$. Strategi ini dilakukan agar kristalisasi dapat lebih cepat. Selain itu, strategi ini secara signifikan dapat mengurangi kandungan padat tersuspensi [20].

Berbeda halnya dengan kolam peminihan, kolam air tua berguna untuk melanjutkan tahapan evaporasi sampai air tua dan dapat dilakukan kristalilasi pada meja garam. Sebelum dipindahkan ${ }^{\circ} \mathrm{Be}$ air tua harus mencapai $25{ }^{\circ}$ Be. Hal ini dikarenakan, jika terlalu rendah akan menimbulkan endapan gips. Hasil pada tambak dekat dan jauh dari pantai didapatkan sangat sesuai (S1) dikarenakan sudah mencapai rentang $25^{\circ} \mathrm{Be}$. Kepekatan air tua yang masuk ke dalam meja garam, akan mempengaruhi kualitas garam. Apabila konsentrasi air tua dibawah $25^{\circ} \mathrm{Be}$, Kalsium Sulfat akan banyak mengendap [15].

Meja garam atau meja kristalisasi merupakan kolam akhir dalam proses pembuatan garam. Meja garam ini memiliki standar air tua yang dapat masuk, yaitu 25 $29^{\circ} \mathrm{Be}$. Penentuan standar air tua ini memang sangat berpengaruh pada hasil mutu garam. Apabila air terlalu muda atau terlalu tua dari rentang ${ }^{\circ} \mathrm{Be}$ tersebut menyebabkan timbul endapan dan perubahan rasa garam. Hasil yang didapatkan pada pengukuran di tambak dekat dan jauh dari pantai adalah sesuai (S2), dimana hasilnya tidak mencapai $29{ }^{\circ} \mathrm{Be}$ yang merupakan air tua maksimal untuk menghasilkan garam. Kadar air tua maksimal adalah $29^{\circ} \mathrm{Be}$, bila lebih dari kadar tersebut magnesium akan banyak mengendap dan menimbulkan garam magnesium yang rasanya pahit [21].

\section{Evaluasi Kesesuaian Lahan Tambak Garam}


Evaluasi kesesuaian lahan tambak garam merupakan analisis yang dilakukan dalam menilai apakah suatu lahan sesuai untuk dijadikan lokasi tambak garam. Fungsi evaluasi ini untuk memberikan pengertian perihal hubungan -hubungan variabel kondisi lingkungan dengan penggunaannya. Evaluasi lahan biasanya memerlukan sifat - sifat fisik yang diistilahkan sebagai karakteristik lahan.
Karakteristik lahan ini nantinya akan dilakukan skoring sesuai dengan pengaruhnya terhadap pembentukan garam. Penentuan kesesuaian lahan dipengaruhi oleh beberapa faktor sebagai dasar pertimbangan lahan yang sangat sesuai dan tidak sesuai serta pemberian skoring. Pemberian skoring tertinggi diberikan kepada nilai parameter yang paling berpengaruh pada pembentukan garam [22].

Tabel 6. Kesesuaian Lahan Tambak Garam Dekat dari Pantai

\begin{tabular}{|c|c|c|c|c|c|}
\hline Variabel Karakteristik Lahan & Hasil Pengukuran & $\begin{array}{c}\text { Bobot } \\
\text { (B) }\end{array}$ & Kategori & $\begin{array}{l}\text { Skor } \\
(\mathrm{S})\end{array}$ & B x S \\
\hline $\mathrm{SO}_{4}(\mathrm{mg} / \mathrm{L})$ & 48.902 & 3 & $\mathrm{~N}$ & 1 & 3 \\
\hline $\mathrm{pH}$ & $6-7$ & 3 & S1 & 3 & 9 \\
\hline Tinggi pematang utama (m) & 1,5 & 1 & $\mathrm{~S} 2$ & 2 & 2 \\
\hline Tinggi pematang antara (m) & 0,4 & 1 & S1 & 3 & 3 \\
\hline Ketinggian air meja garam $(\mathrm{cm})$ & $5-7$ & 5 & S1 & 3 & 15 \\
\hline Dasar tambak & Liat, $3 \%$ pasir & 5 & S1 & 3 & 15 \\
\hline Jarak dari pantai (m) & 410 & 5 & S1 & 3 & 15 \\
\hline Kolam peminihan $\left({ }^{\circ} \mathrm{Be}\right)$ & $10-20$ & 5 & S2 & 2 & 10 \\
\hline Kolam air tua $\left({ }^{\circ} \mathrm{Be}\right)$ & $22-25$ & 5 & S1 & 3 & 15 \\
\hline Meja garam $\left({ }^{\circ} \mathrm{Be}\right)$ & 27 & 5 & S2 & 2 & 10 \\
\hline \multirow[t]{3}{*}{ Dimensi pematang antara } & $\begin{array}{c}\text { Lebar atas } 40 \mathrm{~cm} \text {, } \\
\text { tinggi } 40 \mathrm{~cm}\end{array}$ & 1 & S2 & 2 & 2 \\
\hline & & $\sum \mathrm{Ni}$ & & & 99 \\
\hline & & $\begin{array}{l}\text { Nmaks } \\
\text { IKLG }\end{array}$ & & Sang & $\begin{array}{r}117 \\
\text { Sesuai) }\end{array}$ \\
\hline
\end{tabular}

Keterangan: S1: Sangat Sesuai; S2: Sesuai; N: Tidak Sesuai; IKLG: Indeks Kesesuaian Lahan Garam

Tabel 7. Kesesuaian Lahan Tambak Garam Jauh dari Pantai

\begin{tabular}{|c|c|c|c|c|c|}
\hline Variabel Karakteristik Lahan & Hasil Pengukuran & $\begin{array}{l}\text { Bobot } \\
\text { (B) }\end{array}$ & Kategori & $\begin{array}{l}\text { Skor } \\
\text { (S) }\end{array}$ & B $x \mathrm{~S}$ \\
\hline $\mathrm{SO}_{4}(\mathrm{mg} / \mathrm{L})$ & $13.951,2$ & 3 & $\mathrm{~N}$ & 1 & 3 \\
\hline $\mathrm{pH}$ & 7 & 3 & S1 & 3 & 9 \\
\hline Tinggi pematang utama (m) & 1,5 & 1 & S2 & 2 & 2 \\
\hline Tinggi pematang antara (m) & 0,6 & 1 & S1 & 3 & 3 \\
\hline Ketinggian air meja garam $(\mathrm{cm})$ & $6-7$ & 5 & S1 & 3 & 15 \\
\hline Dasar tambak & Liat, $22 \%$ pasir & 5 & S2 & 2 & 10 \\
\hline Jarak dari pantai (m) & 5.120 & 5 & $\mathrm{~N}$ & 1 & 5 \\
\hline Kolam peminihan $\left({ }^{\circ} \mathrm{Be}\right)$ & $6-18$ & 5 & $\mathrm{~N}$ & 1 & 5 \\
\hline Kolam air tua $\left({ }^{\circ} \mathrm{Be}\right)$ & $22-25$ & 5 & S1 & 3 & 15 \\
\hline Meja garam $\left({ }^{\circ} \mathrm{Be}\right)$ & 26,5 & 5 & S2 & 2 & 10 \\
\hline \multirow[t]{4}{*}{ Dimensi pematang antara } & $\begin{array}{c}\text { Lebar atas } 40 \mathrm{~cm}, \\
\text { tinggi } 60 \mathrm{~cm}\end{array}$ & 1 & S2 & 2 & 2 \\
\hline & \multicolumn{3}{|c|}{$\sum \mathrm{Ni}$} & & 79 \\
\hline & \multicolumn{3}{|c|}{ Nmaks } & & 117 \\
\hline & \multicolumn{3}{|c|}{ IKLG } & \multicolumn{2}{|c|}{$68 \%$ (Sesuai) } \\
\hline
\end{tabular}

Keterangan: S1: Sangat Sesuai; S2: Sesuai; N: Tidak Sesuai; IKLG: Indeks Kesesuaian Lahan Garam 
Hasil evaluasi kesesuaian lahan tambak garam dinilai dari total pembobotan skoring dan Indeks Kesesuaian Lahan Garam (IKLG). Total pembobotan skoring pada tambak dekat dari pantai didapatkan 99 dengan IKLG $85 \%$. Hasil tersebut dikategorikan lahan tambak garam sangat sesuai untuk digunakan. Sementara itu, pada tambak jauh dari pantai didapatkan total pembobotan skoring sebanyak 79 dengan IKLG 68\%. IKLG dengan nilai 68\% digolongkan menjadi sesuai untuk lokasi tambak garam. Hasil evaluasi tersebut dapat menerjemahkan keadaan tambak garam dalam lokasi tersebut sehingga dapat mendukung perkembangan tambak garam tersebut. Kesalahan dalam pemilihan lokasi tambak dapat menimbulkan masalah seperti peningkatan biaya konstruksi dan masalah lingkungan hingga ketidakberhasilannya suatu usaha tambak. Pemilihan lokasi yang tepat diharapkan sesuai dengan teknologi yang digunakan dan kondisi perairan. Oleh karena itu, studi kelayakan dan kesesuaian lahan untuk pertambakan dari aspek teknis perlu dilakukan untuk pengembangannya [17].

Perbandingan hasil evaluasi kesesuaian lahan tambak garam di Desa Tluwuk dengan membandingkan jarak dari pantai, didapatkan lokasi tambak dekat dari pantai lebih baik daripada lokasi tambak jauh dari pantai. Selisih persentase yang cukup tinggi, menyebabkan perbedaan kesesuaian pada kedua lokasi tersebut. Terlihat variabel $\mathrm{Be}$ kolam peminihan dan dasar tambak memiliki pengaruh pada perbedaan hasil di kedua lokasi. Terutama jarak dari pantai memberikan pengaruh paling besar besar dalam hasil skoring. Hal tersebut dikarenakan sumber air dalam proses produksi garam adalah air laut, sehingga semakin dekat dengan sumber air maka lokasi akan semakin sesuai. Hasil analisis menunjukkan bahwa lahan tambak yang sangat sesuai untuk tambak garam ada pada daerah yang dekat dengan garis pantai, hal ini sangat dimungkinkan karena sumber air untuk tambak garam adalah air laut [23].

Hasil evaluasi kesesuaian lahan tambak garam di Desa Tluwuk ini menunjukkan lokasi tersebut masih sesuai untuk dijadikan tambak garam walaupun jarak tambak dengan pantai yang terpaut jauh. Hal tersebut dikarenakan masih terdapat banyak faktor pengaruh lainnya selain jarak yang menilai kesesuaian lokasi tambak garam. Sesuai dengan penelitian terdahulu di Kabupaten Tuban, dimana lokasi tambak garam tidak berada langsung di tepi laut, tetap memiliki sumber air bahan baku dengan tingkat kejenuhan yang cukup $\left( \pm 2{ }^{\circ} \mathrm{B}\right)$. Hal ini yang menyebabkan walaupun tidak berada langsung di tepi laut, lokasi ini bisa digunakan sebagai lokasi tambak garam, sehingga hasil analisis keseluruhan parameter dalam IKLG di Kabupaten Tuban sudah sangat sesuai untuk proses produksi [1].

Kualitas dan produktivitas garam yang dihasilkan dimungkinkan selain dipengaruhi oleh variabel kesesuaian tambak garam, dipengaruhi pula oleh variabel lain seperti penggunaan teknologi geomembrane serta faktor klimatologi. Teknologi geomembrane adalah pelapisan tanah dasar tambak dengan material dari bahan plastik High Density Polyethylene (HDPE). Penggunaan teknologi geomembrane sangat membantu dalam proses penguapan air laut yang semakin cepat dikarenakan sifat plastik yang dapat menyerap radiasi matahari. Selain iu, penggunaan teknologi ini akan menghasilkan garam yang lebih putih dan bersih akibat terlindungnya dari kontaminasi sedimen dasar kolam [24].

Faktor klimatologi seperti pergantian musim, kecepatan angin dan radiasi matahari akan berpengaruh pada kuantitas garam yang dihasilkan. Lama terjadinya musim kemarau di daerah produksi garam akan mempengaruhi tingkat penguapan air di daerah produksi garam. Faktor lainnya seperti kecepatan angin dan lama radiasi matahari juga akan berpengaruh pada laju penguapan atau laju evaporasi. Semakin tinggi laju evaporasi ini akan menghasilkan jumlah kristal yang tinggi pula [1].

\section{KESIMPULAN}


Kesesuaian lahan tambak garam di Desa Tluwuk, Kecamatan Wedarijaksa, Kabupaten Pati termasuk kategori sangat sesuai dengan Indeks Kesesuaian Lahan Garam (IKLG) 85\% untuk tambak yang dekat dari pantai dan termasuk kategori sesuai dengan IKLG 68\% untuk tambak yang jauh dari pantai.

\section{UCAPAN TERIMA KASIH}

Penulis mengucapkan terima kasih Ibu Sriwati dan Bapak Agus Purnomo sebagai pendamping lapangan dalam pengambilan data penelitian ini.

\section{DAFTAR PUSTAKA}

[1] Kurniawan, A., A. A. Jaziri, A. A. Amin dan L. N. Salama. 2019. Indeks Kesesuaian Garam (IKG) Untuk Menentukan Kesesuaian Lokasi Produksi Garam; Analisis Lokasi Produksi Garam di Kabupaten Tuban dan Kabupaten Probolinggo. Journal of Fisheries and Marine Research, 3(2): 236-244.

[2] Dinas Kelautan dan Perikanan Kabupaten Pati. 2020.

[3] Lad, H., V. Joshi dan R. Makavana. 2015. Natural Evaporation Type Salt Manufacturing Process Resource Management Using Distributed Embedded System. International Journal Of Computer Applications, 117(23).

[4] Arwiyah, M. Zainuri dan M. Efendy. 2015. Studi Kandungan $\mathrm{NaCl}$ di Dalam Air Baku dan Garam yang Dihasilkan Serta Produktivitas Lahan Garam Menggunakan Media Meja Garam yang Berbeda. Jurnal Kelautan, 8(1): 1-9.

[5] Adimas, S. Hasudungan, Suharyanto, dan R. J. Kodoatie. 2015. Kajian Kelayakan Ekonomi Jaringan Tambak Garam Lepas Pantai di Sampang
Madura. Jurnal Karya Teknik Sipil, 4(1): 1- 9 .

[6] Wibisono, G. 2018. Penaksiran Volume Pohon Komersil Melalui Metode Penarikan Acak Berlapis (Stratified Random Sampling) Berdasarkan Kelas Lereng dan Kerapatan Tegakan di PT. Limbang Ganeca. J Hut Trop, 2(2): 6559.

[7] Setiawan, W. 2018. Studi Kesesuaian Wilayah Pesisir Sebagai Lahan Tambak Garam di Kecamatan Palang Kabupaten Tuban. Prosiding Seminar Nasional Hasil Penelitian dan Pengabdian Kepada Masyarakat III. Universitas PGRI Ronggolawe Tuban : 215-220.

[8] Nugraha, H. P., A. Indarjo dan M. Helmi. 2013. Studi Kesesuaian dan Daya Dukung Kawasan untuk Rekreasi Pantai di Pantai Panjang Kota Bengkulu. Journal of Marine Research, 2(2): 130139.

[9] Rusiyanto, E.Soesilowati dan Jumaeri. 2013. Penguatan Industri Garam Nasional Melalui Perbaikan Teknologi Budidaya dan Diversifikasi Produk. Sainteknol, 11(2): 129-142.

[10] Sukoasih, A., T. Widiyanto dan Suparmin. 2017. Hubungan Antara Suhu, pH dan Berbagai Variasi Jarak Dengan Kadar Timbal $(\mathrm{Pb})$ pada Badan Air Sungai Rompang dan Air Sumur Gali Industri Batik Sokaraja Tengah Tahun 2016. Jurnal Poltekkes Semarang, 36(4): 360-368.

[11] Yasir, M. dan M. Nur. 2018. Analisis Pendapatan Petani Tambak di Kabupaten Luwu. Economic Resources, 1(1): 16-30.

[12] Rabby, H., Suwandi dan E. Wibowo. 2017. Analisa Pengaruh Temperatur, Kelembaban, Intesitas Cahaya, Lama Penyinaran, dan Konsentrasi Larutan Terhadap Penguapan Air Garam dalam 
Disitilator. E-Proceeding of Engineering, 4(1): 572-579.

[13] Junas dan F. Surur. 2019. Arahan Kesesuaian Lahan Pertambakan Garam di Kecamatan Bangkala Kabupaten Jeneponto. Jurnal OPTIMA, 3(2): 17-23.

[14] Afrianita, R., T. Edwin dan A. Alawiyah. 2017. Analisis Intrusi Air Laut dengan Pengukuran Total Disolved solids (TDS) Air Sumur Gali di Kecamatan Padang Utara. Jurnal Teknik Lingkungan UNAND, 14(1): 62- 72.

[15] Sartono, C. M., P. Soedarsono dan M. R. Muskanonfola. 2013. Konversi Tonase Air dengan Berat Garam yang Terbentuk di Areal Pertambakan Tanggultlare Jepara. Journal of Management of Aquatic Resources, 2 (3 : 20-26.

[16] Dewi, K. K. dan M. Widyastuti. 2016. Kajian Perubahan Kualitas Air Sungai Donan Kabupaten Cilacap Tahun 1998 dan 2015. Jurnal Bumi Indonesia, 5(3).

[17] Hasan, H. dan H. Yanto. 2018. Aspek Teknis Analisis Kesesuaian Lahan Pertambakan di Desa Suka Baru Kecamatan Benua Kayong Kabupaten Ketapang . Jurnal Ruaya, 6(1): 74-84.

[18] Ratnawati, E. dan A. I. Asaad. 2012. Daya Dukung Lingkungan Tambak di Kecamatan Pulau Derawan dan Sambaliung, Kabupaten Berau, Provinsi Kalimantan Timur. Jurnal Ilmiah Perikanan dan Kelautan, 4(2): 175-184.

[19] Effendy, M., M. Zainuri dan Hafiludin. 2014. Intensifikasi Lahan Garam Rakyat di Kabupaten Sumenep. Jurnal Ilmu Kelautan Turnojoyo, 2(3): 22-43.

[20] Susanto, H., N. Rokhati dan G. W. Santosa. 2015. Development of Traditional Salt Production Process for Improving Product Quantity and Quality in Jepara District, Central Java, Indonesia. Procedia Environmental Science, 23: 175-178.

[21] Santosa, I. 2014. Pembuatan Garam Menggunakan Kolam Kedap Air Berukuran Sama. Spektrum Industri, 12(1): 85-91.

[22] Latjolai, M. dan N. Auliyah. 2019. Kesesuaian Lahan Tambak Garam Di Desa Siduwonge Kecamatan Randangan Kabupaten Pohuwato. Gorontalo Fisheries Journal, 2(1 : 29-36.

[23] Muhsoni, F. F. 2012. Kesesuaian Lahan Tambak Garam Menggunakan Sistem Informasi Geograffis di Kabupaten Sampang. Prosiding Seminar Nasional Kedaulatan Pangan dan Energi. Universitas Trunojoyo Madura.

[24] Abdullah, Z. A. dan A. Susandini. 2018. Media Produksi (Geomembrane) Dapat Meningkatkan Kualitas dan Harga Jual Garam (Study Kasus : Ladang Garam Milik Rakyat di Wilayah Madura). EcoEntrepreneurship, 3(2): 21-36. 